\title{
Altered Neural Cholinergic Receptor Systems in Cocaine-Addicted Subjects
}

\author{
Bryon Adinoff*, 1,2, Michael D Devous Sr ${ }^{3}$, Mark J Williams', Susan E Best ${ }^{1,2}$, Thomas S Harris ${ }^{3}$, \\ Abu Minhajuddin ', Tanya Zielinski' and Munro Cullum' \\ 'Department of Psychiatry, University of Texas Southwestern Medical Center, Dallas, TX, USA; ${ }^{2}$ VA North Texas Health Care System, Dallas, TX, \\ USA; ${ }^{3}$ Nuclear Medicine Center and Department of Radiology, University of Texas Southwestern Medical Center, Dallas, TX, USA; ${ }^{4}$ Department \\ of Clinical Sciences, University of Texas Southwestern Medical Center, Dallas, TX, USA
}

\begin{abstract}
Changes in the brain's cholinergic receptor systems underlie several neuropsychiatric disorders, including Alzheimer's disease, schizophrenia, and depression. An emerging preclinical literature also reveals that acetylcoholine may have an important function in addictive processes, including reward, learning, and memory. This study was designed to assess alterations in cholinergic receptor systems in limbic regions of abstinent cocaine-addicted subjects compared with healthy controls. On three separate days, 23 I- to 6-week abstinent, cocaine- (and mostly nicotine-) addicted subjects and 22 sex-, age-, and race-matched control subjects were administered the muscarinic and nicotinic cholinergic agonist physostigmine, the muscarinic antagonist scopolamine, and saline. Regional cerebral blood flow (rCBF) after each infusion was determined using single photon emission-computed tomography. Both cholinergic probes induced rCBF changes $(p<0.005)$ in relatively distinct, cholinergic-rich, limbic brain regions. After physostigmine, cocaine-addicted subjects showed altered $\mathrm{rCBF}$, relative to controls, in limbic regions, including the left hippocampus, left amygdala, and right insula. Group differences in the right dorsolateral prefrontal cortex, posterior cingulate, and middle temporal gyrus were also evident. Scopolamine also revealed group differences in the left hippocampus and right insula as well as the posterior cingulate and middle temporal gyrus. Cocaine addicted and controls differ in their subcortical, limbic, and cortical response to cholinergic probes in areas relevant to craving, learning, and memory. Cholinergic systems may offer a pharmacologic target for cocaine addiction treatment.

Neuropsychopharmacology (2010) 35, |485-1499; doi:10.1038/npp.2010.18; published online 10 March 2010
\end{abstract}

Keywords: addiction and substance abuse; imaging; clinical or preclinical; acetylcholine; biological psychiatry; cocaine addiction

\section{INTRODUCTION}

Acetylcholine (ACh) mediates reinforcement, satiation, the acquisition of conditional associations that underlie drug craving and drug sensitization, the development of stimulus response associations in habit learning, and drug procurement through its effects on arousal and attention (Williams and Adinoff, 2008). In addition, ACh and its target receptors are prominent in subcortical and cortical structures important to drug reward, self-administration, and the addictive use of substances. For example, the effect of ACh on reward-relevant processes is due, at least in part, to $\mathrm{ACh}$ projections on ventral tegmental area dopaminergic efflux (Clarke and Pert, 1985; Weiner et al, 1990) and the subsequent effect of dopamine (DA) release on striatal ACh interneurons (Berlanga et al, 2005; Consolo et al,

\footnotetext{
*Correspondence: Dr B Adinoff, Department of Psychiatry, University of Texas Southwestern Medical Center, 5323 Harry Hines Boulevard, Dallas, TX 75390-8564, USA, Tel: + I 2146456975 , Fax: + I 214645 6976, E-mail: bryon.adinoff@utsouthwestern.edu

Received 18 November 2009; revised 14 January 2010; accepted I5 January 2010
}

1999). Striatal cholinergic output then further modulates striatal DA efflux (Zhang et al, 2002). Through these mechanisms, the ACh and DA systems seem to coordinate striatal reward in a feed-forward, complementary manner (Zhou et al, 2003).

Preclinical evidence of a function for ACh in drug-related behaviors has been strongest for cocaine (see review in Williams and Adinoff, 2008). Striatal (Berlanga et al, 2003; Crespo et al, 2006; Mark et al, 1999) and hippocampal (Imperato et al, 1996; Smith et al, 2004a; Smith et al, 2004b) increases in ACh are associated with the acquisition of cocaine; in rodents, the run time (how fast an animal runs to obtain a contingent stimulus) is inversely correlated to nucleus accumbens (NAc) ACh release during cocaine acquisition (Crespo et al, 2006), NAc ACh neuronal activation is directly correlated with the amount of cocaine self-administered (Berlanga et al, 2003), and cholinergic input into the amygdala has a function in the cognitive processes involved in the learning and memory of drugassociated cues (Schroeder and Packard, 2004; See et al, 2003). Indirect evidence also suggests that the relevance of ACh to attentional (Robbins, 2002; Sarter et al, 2003) and decision-making (Chen et al, 2004; Ragozzino and Choi, 
2004) processes may impact the observed deficits that many cocaine-addicted subjects show in these neurocognitive domains (Adinoff et al, 2007; Horner et al, 1996; Jovanovski et al, 2005). Substance-induced alterations in cholinergic systems, therefore, could reasonably be expected to alter both reward and cognitive systems relevant to the addictive process (Williams and Adinoff, 2008).

There are two major classes of ACh receptors: the nicotinic receptor ( $\mathrm{nAChR}$ ) and muscarinic receptor (mAChR). The relevance of the nAChR to nicotine (Mansvelder et al, 2003) and, more recently, cocaine (Williams and Adinoff, 2008) dependence have been well described. Of equal interest, however, is the impact of the $\mathrm{mACh}$ receptor on cocaine-induced reward and administration. The rewarding effects of cocaine are mediated by $\mathrm{M}_{5}$ receptors in the ventral tegmentum (Fink-Jensen et al, 2003; Thomsen et al, 2005; Yeomans et al, 2001) and $\mathrm{M}_{5}$-deficient rats show an attenuation of cocaine-induced conditioned place preference (Fink-Jensen et al, 2003). Several investigators have observed alterations in striatal $\mathrm{mACh}$ receptors after chronic cocaine administration (Lipton et al, 1995; Macedo et al, 2004). In addition to the effects of cocaine mediated by dopaminergic efflux, cocaine itself has direct effects on $\mathrm{M}_{1}$ and $\mathrm{M}_{2}$ (Flynn et al, 1992b; Karpen and Hess, 1986; Sharkey et al, 1988b) receptors. In human studies, polymorphisms of the mAChR M2 gene (CHRM2) have recently been shown to be involved in a general externalizing phenotype predictive of substance-use disorders (Dick et al, 2008).

The ACh system, therefore, offers itself as a potential target for pharmacologic manipulation in the treatment of cocaine dependence. Although clinical studies have offered suggestive evidence of such an approach, the direction of change has been puzzling. Early studies reported a decrease in cocaine self-administration in non-human primates after treatment with either physostigmine, an acetylcholinesterase (AChE) inhibitor (de la Garza and Johanson, 1982) (which increases cholinergic activity) or atropine, an mACh antagonist (which presumably decreases ACh activity) (Wilson and Schuster, 1973). De la Garza et al (2008) have also recently reported that the AChE inhibitor, rivastigmine, decreased methamphetamine-induced craving during selfadministration in human volunteers. On the other hand, a preliminary study using donepezil, another cholinesterase inhibitor, did not attenuate cocaine use in a treatmentseeking population (Winhusen et al, 2005).

To our knowledge, there have been no published controlled human studies exploring cholinergic receptor functioning in cocaine-dependent subjects. Given the high concentration of cholinergic receptors in the limbic system, particularly in the amygdala and hippocampus, and the importance of this system to rewarding and addictive behaviors, we hypothesized that limbic regions would be significantly altered in cocaine-dependent individuals compared with healthy controls. We used two cholinergic probes to assess cholinergic functioning. Physostigmine, a cholinergic agonist, was used to concurrently assess muscarinic and nAChRs and scopolamine was used to selectively assess mAChRs. We predicted that areas dominant in mAChRs would have opposite regional cerebral blood flow ( $\mathrm{rCBF}$ ) responses to physostigmine and scopolamine. We also expected that regions dominant in nAChRs would show a response to physostigmine, but not scopolamine. The $\mathrm{rCBF}$ was measured in response to each of the two probes as well as a saline comparison. Whereas neuroreceptor radiotracers are used to study preand post-synaptic sites, $\mathrm{rCBF}$ is used to assess the integrated response to receptor-specific probes, including downstream effects. Thus, our paradigm measured the combined muscarinic and nicotinic (with physostigmine) and muscarinic only (with scopolamine) impact on neuronal function at both the receptor site and the downstream neurons influenced by these receptors. We also chose these probes because of their extensive history of safety in human beings and their earlier use in neuroimaging studies, allowing appropriate dosing to be selected.

\section{MATERIALS AND METHODS}

\section{Participants}

Twenty-three (12 male) cocaine-addicted and 22 (12 male) healthy control subjects were studied. Cocaine-addicted subjects had a primary DSM-IV diagnosis of cocaine dependence and cocaine was their lifetime drug of choice. They were 1-6 weeks abstinent [range 8-39 days; 27.4 (SD 7.3)], which offered a relatively circumscribed period of abstinence, acclimation to the residential unit, and adequate time for the most marked effects of cocaine withdrawal to subside (Weddington et al, 1990). Cocaine-addicted subjects were recruited from patients requesting treatment for cocaine dependence at the Veteran's Administration Medical Center $(n=11)$, Homeward Bound, $(n=4)$, and Nexus Recovery Center $(n=8)$ in Dallas, Texas. Abstinence was verified throughout their residential program by urine drug screens at least three times a week at the VA Medical Center, random screens at least weekly and after all passes at Homeward Bound, and random screens at least every 2 weeks and after all passes at Nexus Recovery Center. Addicted subjects were hospitalized as soon as possible after their last reported use of cocaine and remained in a structured, residential unit until the study was completed. Exclusion criteria included a substance-use disorder (other than cocaine or nicotine) within the earlier 6 months, present use of any central nervous system (CNS) active medications, or a lifetime history for affective, anxiety, or schizophrenic disorder, or organic brain syndrome experienced before the onset of a substance-abuse diagnosis or after a period of at least 3 months abstinence. Exclusion criteria for healthy controls included the criteria as noted for the cocaine-addicted subjects, as well as a lifetime history of any other Axis I disorder (except nicotine dependence) or a first-degree relative with an addictive disorder (other than nicotine).

After providing a complete description of the study to the subjects, written informed consent was obtained. Subjects were financially compensated for their participation. Approval for the study was obtained from the Institutional Review Board of the University of Texas Southwestern Medical Center at Dallas (UTSW) and the VA North Texas Health Care System. Subjects underwent a medical history and physical examination, DSM-IV structured clinical interview (First et al, 2002), clinical laboratory tests, urine drug screen, electrocardiogram, narrow-angle glaucoma 
screening, and clinical MRI. Lifetime cocaine and other substance-use history was obtained from cocaine-dependent subjects using the time line follow back (Sobell and Sobell, 1978).

\section{Single Photon Emission-Computed Tomography Study Sessions}

Study sessions took place at the Clinical Trials Office at the UTSW. Cocaine-addicted subjects were transported directly from their treatment program. Subjects underwent four study sessions over a 10-day period. For one session, only a saline placebo was administered; for the other sessions, subjects received either physostigmine, scopolamine, or ondansetron (ondansetron data not presented here). Sessions were separated by at least $48 \mathrm{~h}$ to allow time for decay of ${ }^{99 \mathrm{~m}} \mathrm{TcHMPAO}$, which has a half-life of $\sim 6 \mathrm{~h}$. The four scans were administered in a pseudorandom order to assure randomization and to avoid having the two cholinergic probes administered back to back. Thus, at least $96 \mathrm{~h}$ separated the physostigmine and scopolamine scans. Owing to technical problems, a physostigmine scan was not obtained on one cocaine-addicted subject and scopolamine scans were not obtained on two control subjects.

Nicotine-dependent subjects were allowed a cigarette 30 min before study initiation $(\sim 2 \mathrm{~h}$ before radioligand administration). This timing was long enough to avoid the acute effects of nicotine, whereas short enough to avoid the onset of nicotine withdrawal. Subjects were placed supine in a recliner, at rest, with eyes open, and ears unplugged. An intravenous catheter was inserted at $\sim 1400$ hours $(T=-30 \mathrm{~min})$ and a continuous infusion of saline was given throughout the study (except when medication was being administered). The Brief Symptom Inventory (BSI) (Derogatis and Melisaratos, 1983) was administered after $30 \mathrm{~min}$ of rest $(T=0)$ and just before radioligand administration. The BSI uses 53 questions to assess cognitive, sensory, and affective changes. Blood pressure and heart rate were obtained every $10 \mathrm{~min}$ throughout the study and vagal tone was recorded continuously (data not reported here). Medications were administered through the intravenous line hidden behind a curtain, and all subjects and the study coordinator were blinded to study drug.

Physostigmine was administered as described by Furey et al (2000) (Figure 1). Glycopyrrolate, a cholinergic antagonist that does not have central effects, was administered $5 \mathrm{~min}$ before physostigmine $(T=0)$ to block physostigmine's peripheral side effects (ie nausea). Owing to physostigmine's short half-life ( $\sim 20 \mathrm{~min})$, a loading dose of $1.93 \mathrm{mg} / \mathrm{h} \times 10 \mathrm{~min}$ was then administered to achieve steady-state levels $(T=5-15)$, followed by a maintenance rate of $0.816 \mathrm{mg} / \mathrm{h}$ for $50 \mathrm{~min}(T=15-65)$. Scopolamine $4.5 \mu \mathrm{g} / \mathrm{kg}$, or $0.315 \mathrm{mg}$ for $70 \mathrm{~kg}$ person, was administered at $T=5 \mathrm{~min}$ by intravenous push over $1 \mathrm{~min}$ and $55 \mathrm{~min}$ before radioligand administration (Ahveninen et al, 1999; Blin et al, 1994b; Meador et al, 1995a, b). The long half-life of scopolamine $(9.5 \mathrm{~h})$ allowed a single bolus to be infused. A total of $20 \mathrm{mCi}$ of the single photon emission-computed tomography (SPECT) rCBF tracer ${ }^{99 \mathrm{~m}} \mathrm{Tc}$ HMPAO (GE Healthcare, Princeton, New Jersey, USA) was then administered over $30 \mathrm{~s}$ and followed by a $10 \mathrm{ml}$ saline flush over $30 \mathrm{~s}$ at
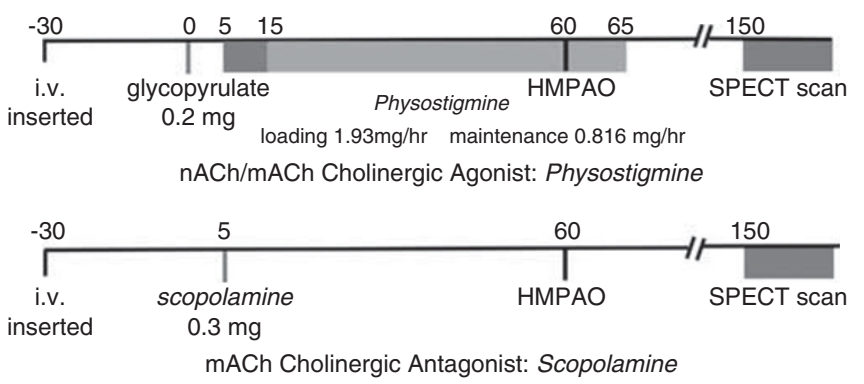

Figure I Flowchart of physostigmine, scopolamine, and ondansetron infusions. Four sessions, each at least $48 \mathrm{~h}$ apart, were conducted over 10 days. In addition to the three infusions noted, a saline infusion was administered on a separate day. Session order was pseudorandomized to assure randomization and to avoid having the two cholinergic probes (physostigmine and scopolamine) administered in consecutive sessions.

$T=60 \mathrm{~min}$. Twenty minutes after the radioligand infusion, the intravenous catheter(s) was removed and a Subjective Symptom Inventory was obtained. The Subjective Symptom Inventory asked subjects to rate (from 0 to 5) 20 signs and symptoms (ie shakiness, blurred vision, headache, sadness, anxiety, drowsiness, etc.) potentially experienced during the study. SPECT scans were obtained $90 \mathrm{~min}$ after ${ }^{99 \mathrm{~m}} \mathrm{Tc}$ HMPAO administration to allow time for tracer activity to clear from blood and non-brain tissues. As ${ }^{99 \mathrm{~m}} \mathrm{Tc}$ HMPAO is extracted during the first arterial pass and remains distributed in the brain in proportion to $\mathrm{rCBF}$ for many hours, this perfusion image represents $\mathrm{rCBF}$ at the time of radiotracer administration and not at the time of the scan.

\section{SPECT Imaging Analysis}

SPECT images were acquired on a PRISM 3000S threeheaded SPECT camera (Picker International, Cleveland, OH, USA) using ultra-high-resolution fan-beam collimators (reconstructed resolution of $6.5 \mathrm{~mm}$ ) in a $128 \times 128$ matrix in three-degree increments. For our system, voxels in reconstructed images were $1.9 \mathrm{~mm}^{3}$. Reconstructed images were smoothed with a sixth-order Butterworth threedimensional filter, and attenuation corrected using a Chang first-order method with ellipse size adjusted for each slice.

\section{Statistical Analysis}

Demographic and clinical data. Demographic and clinical characteristics were compared using ANOVA F or $\chi^{2}$ tests as appropriate. Basal and medication-induced (post- $v s$ preinfusion) changes in BSI, heart rate, and blood pressure were assessed using ANOVA $F$ tests. False discovery rate techniques (Benjamini and Hochberg, 1995) were used to control the type I error rate for the large number of comparisons.

Image analysis. SPECT images were resliced to $2 \mathrm{~mm}^{3}$ voxels, co-registered to Montreal Neurologic Institute (MNI) space using the MNI T1 MRI template, smoothed to a final resolution of $10 \mathrm{~mm}$ and normalized to whole brain counts (to correct for individual variability in global 
cerebral blood flow). Relative rCBF in healthy subjects has low variance across subjects and is relatively stable over time within subjects (Devous, 2002). The accuracy of spatial normalization of functional brain images (SPECT, PET, and fMRI) is limited by the spatial resolution of the original data $(6 \mathrm{~mm}$ for these data), by partial volume effects, and by the limits of the normalization algorithm used. Thus, the accuracy of normalization in our data is about $2-4 \mathrm{~mm}$, and the anatomic designations assigned to observed rCBF effects are constrained by these limitations, as well as by our spatial resolution and partial volume effects.

Voxel-wise analyses (voxel Z-scores $=p<0.005$, cluster size $>100$ voxels) comparing saline- and physostigmine/ scopolamine-induced effects were conducted using Statistical Parametric Mapping (SPM2; University College, London, England). Significant changes induced by physostigmine and scopolamine were computed relative to saline. Between-group differences after physostigmine and scopolamine were also assessed $(p<0.005$, cluster size $>50)$.

Regions of interest defined by cluster boundaries for eight regions we considered relevant to addictive processes were also identified and the average $\mathrm{rCBF}$ within each cluster was determined for each subject in each condition. Group differences were obtained by $t$-test and Pearson product moment correlation was used to assess the association between clusters and cocaine or nicotine use in cocaineaddicted subjects. As comparisons are for relative measures, they cannot identify the absolute direction of differences. For example, a heightened $\mathrm{rCBF}$ response in cocaineaddicted subjects compared with controls may indicate a greater relative increase in $\mathrm{rCBF}$ in cocaine-addicted subjects compared with controls, a greater decrease in rCBF response in controls relative to cocaine-addicted subjects, or a combination of both. Owing to the decreased power of a contrast of differences requiring significant differences both within and between groups, cluster size was lowered to 50 voxels. To clarify the direction of change observed in the between-group comparisons, within-group comparisons were also performed at less conservative $p$-values $(p<0.05,<0.01)$ to identify whether controls or cocaine-addicted subjects were driving the between-group differences.

Regions of interest defined by cluster boundaries for eight regions we considered relevant to addictive processes were also identified and the average $\mathrm{rCBF}$ within each cluster was determined for each subject in each condition. Group differences were obtained by $t$-test and Pearson product moment correlation was used to assess the association between clusters and cocaine or nicotine use in cocaineaddicted subjects.

\section{RESULTS}

\section{Demographics}

Control and cocaine-addicted populations were gender matched (see Table 1) and did not significantly differ in race or age. The cocaine-addicted group had more smokers $(22 / 23$ smoked) relative to the control group (6/22 smoked) and a lower mean level of education.

Table I Demographic Characteristics of Control and Cocaine-Addicted Subjects

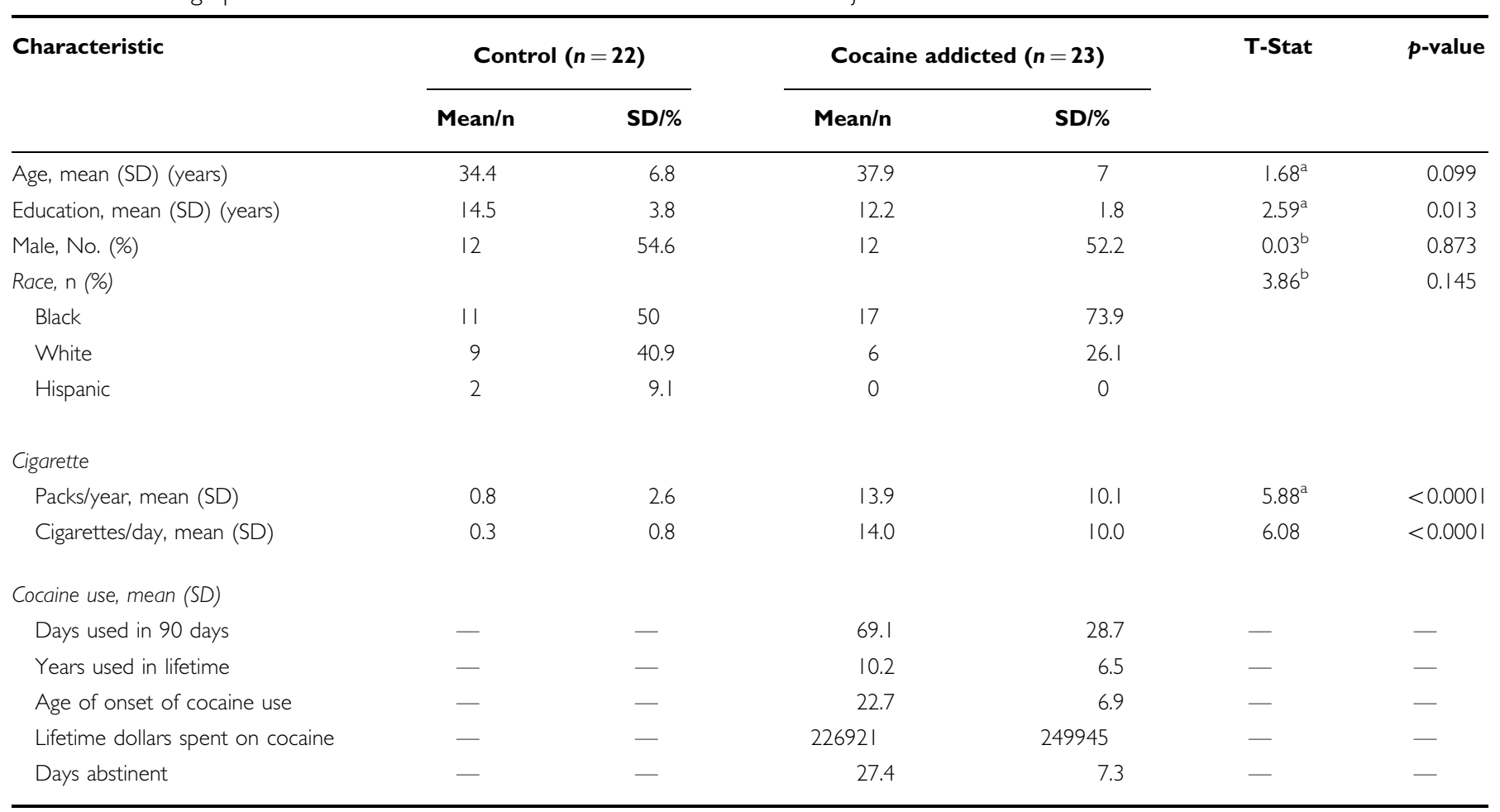

a Values obtained by $t$-test.

bValues obtained by $\chi^{2}$ test. 

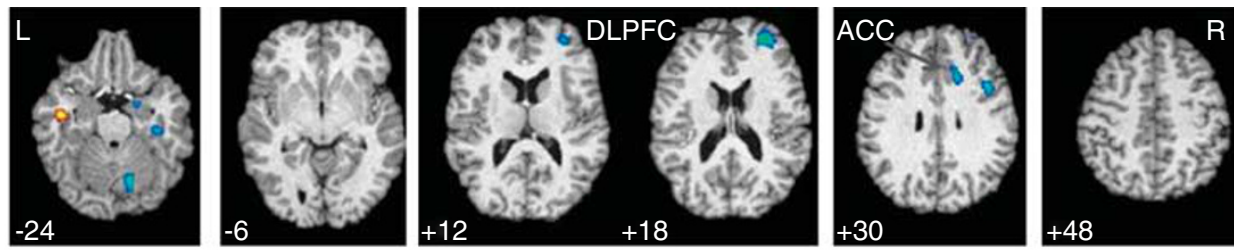

Cocaine-addicted
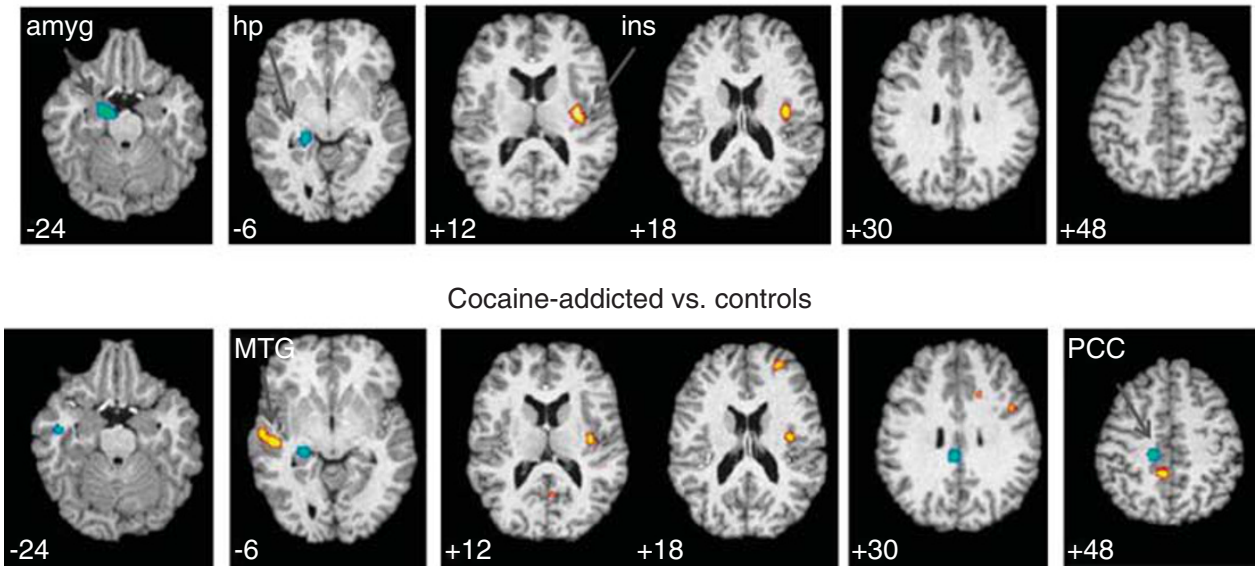

Cocaine-addicted vs. controls
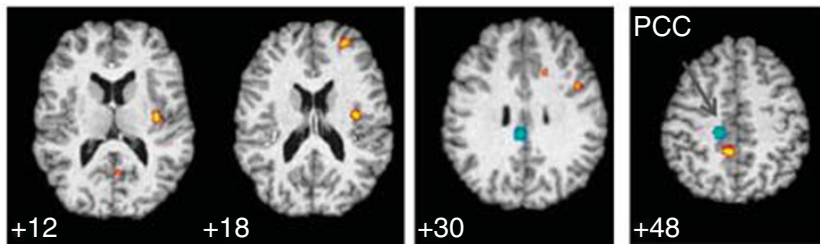

Figure 2 Regional cerebral blood flow (rCBF) changes in response to physostigmine relative to saline $(p<0.005)$ in 22 control and 22 cocaine-addicted (middle panel) subjects. In upper and middle panels, yellow areas reveal voxels with increased rCBF after physostigmine relative to saline and blue areas reveal voxels with decreased rCBF after physostigmine relative to saline. Bottom panel displays comparison between cocaine-addicted (physostigmine-saline) and control (physostigmine — saline) subjects. Yellow areas display voxels with greater rCBF response to physostigmine in patients relative to controls; blue areas are voxels with decreased rCBF response in patients relative to controls. MNI coordinates ( $Z$ axis) noted at the bottom left of each image. $\mathrm{L}=$ left; $\mathrm{R}=$ right; $\mathrm{DLPFC}=$ dorsolateral prefrontal cortex; $\quad \mathrm{ACC}=$ anterior cingulate cortex; amyg $=$ amygdala; $h p=$ hippocampus; ins $=$ insula; MTG = middle temporal gyrus; PCC = posterior cingulate cortex. See Supplement I (controls), Supplement 2 (cocaine addicted), and Supplement 3 (comparison images) for all transverse images.

\section{rCBF After Physostigmine}

After administration of the cholinergic agonist physostigmine, compared with saline, control subjects $(n=22)$ showed a relative $\mathrm{rCBF}$ decrease in right amygdala, right dorsolateral prefrontal cortex (DLPFC), and right anterior cingulate (Figure 2, top panel; Table 2). Cocaine-addicted subjects $(n=22)$ (Figure 2, middle panel) showed an $\mathrm{rCBF}$ decrease in left posterior hippocampus (cluster overlaps hippocampal tail) and left amygdala, and an increase in right posterior insula. Hippocampal changes are illustrated in further detail in Figure 3 along with individual subject data.

Comparisons between groups (Figure 2, lower panel) showed that cocaine-addicted relative to control subjects had decreases in left hippocampus and posterior cingulate and increases in right posterior insula, middle temporal gyrus, DLPFC, and a region of the posterior cingulate posterior to where the decrease is located. A comparison of the top and middle panels of Figure 2 indicates that the DLPFC increase seen in the bottom panel is primarily a consequence of decreases in $\mathrm{rCBF}$ in the region experienced by normal controls, whereas the increase in right insula is driven by increases in the area in the addicted subjects. Similarly, the decrease in left posterior hippocampus is driven by changes in the cocaine-addicted group. Left posterior cingulate increases and decreases were driven by changes evident only at a $p<0.01$ threshold; controls increased and cocaine-addicted subjects decreased $\mathrm{rCBF}$ in nearly identical regions.

SPM-derived clusters showed a significant difference between groups in three predicted limbic regions [left posterior hippocampus/hippocampal tail $(p=0.027)$, left amygdala $(p=0.027)$, right posterior insula $(p=0.005)]$ as well as in the limbically innervated right DLPFC $(p=0.005)$ (Table 3).

\section{rCBF After Scopolamine}

After scopolamine relative to saline, the posterior hippocampus/left hippocampal region again showed decreased $\mathrm{rCBF}$ in cocaine-addicted subjects $(n=23)$ (Figure 4, middle panel; Table 4). Note the striking similarity in the response in posterior hippocampus in addicted subjects for both physostigmine and scopolamine. In fact, cocaineaddicted subjects showed a significant correlation between physostigmine and scopolamine $\mathrm{rCBF}$ in this region $(r=0.62, \mathrm{df}=22, p<0.002)$. Non-limbic regions showing scopolamine-induced rCBF changes in controls (Figure 4, top panel) included right DLPFC and left posterior cingulate (increases) and right thalamus and medial orbitofrontal cortex (decreases). Cocaine-addicted subjects also showed significant $\mathrm{rCBF}$ changes in left DLPFC, an area adjacent to left anterior cingulate (increases), and left midbrain 
Table 2 Brain Regions Demonstrating Increased and Decreased ( $p<0.005$ ) Regional Cerebral Blood Flow (rCBF) After Physostigmine Compared with Saline in Healthy Controls and Cocaine-Dependent Subjects

\begin{tabular}{|c|c|c|c|c|c|c|}
\hline \multirow[t]{2}{*}{ Identified region } & \multicolumn{3}{|c|}{ MNI coordinates } & \multirow[t]{2}{*}{$k_{E}^{a}$} & \multirow[t]{2}{*}{ Z-score } & \multirow{2}{*}{$\begin{array}{l}\text { Cluster-level } \\
\text { uncorrected }\end{array}$} \\
\hline & $x$ & $Y$ & $\mathbf{Z}$ & & & \\
\hline \multicolumn{7}{|l|}{ Healthy controls } \\
\hline \multicolumn{7}{|l|}{ Increased rCBF } \\
\hline $\mathrm{L}$ middle temporal gyrus & -48 & -10 & -26 & 138 & 4.26 & 0.05 \\
\hline $\mathrm{R}$ dorsolateral prefrontal cortex ${ }^{\mathrm{b}}$ & 28 & 56 & 20 & 233 & 4.09 & 0.014 \\
\hline R amgydala & 24 & 0 & -16 & 145 & 3.24 & 0.046 \\
\hline $\mathrm{R}$ anterior cingulate & 16 & 22 & 28 & 107 & 3.21 & 0.080 \\
\hline $\mathrm{R}$ middle frontal gyrus & 44 & 14 & 34 & 160 & 3.50 & 0.037 \\
\hline \multicolumn{7}{|l|}{ Increased rCBF } \\
\hline R post-insulab & 36 & -10 & 12 & 164 & 3.85 & 0.036 \\
\hline \multicolumn{7}{|l|}{ Decreased rCBF } \\
\hline $\mathrm{L}_{\text {amygdala }}{ }^{\mathrm{b}}$ & -20 & -6 & -24 & 189 & 3.73 & 0.026 \\
\hline L hippocampus, tail ${ }^{b}$ & -20 & -32 & -6 & 122 & 3.13 & 0.065 \\
\hline
\end{tabular}

${ }^{\mathrm{a} C l u s t e r ~ s i z e . ~}$

${ }^{\mathrm{b}}$ Regions of interests considered in Table 2 and in covariate analysis.

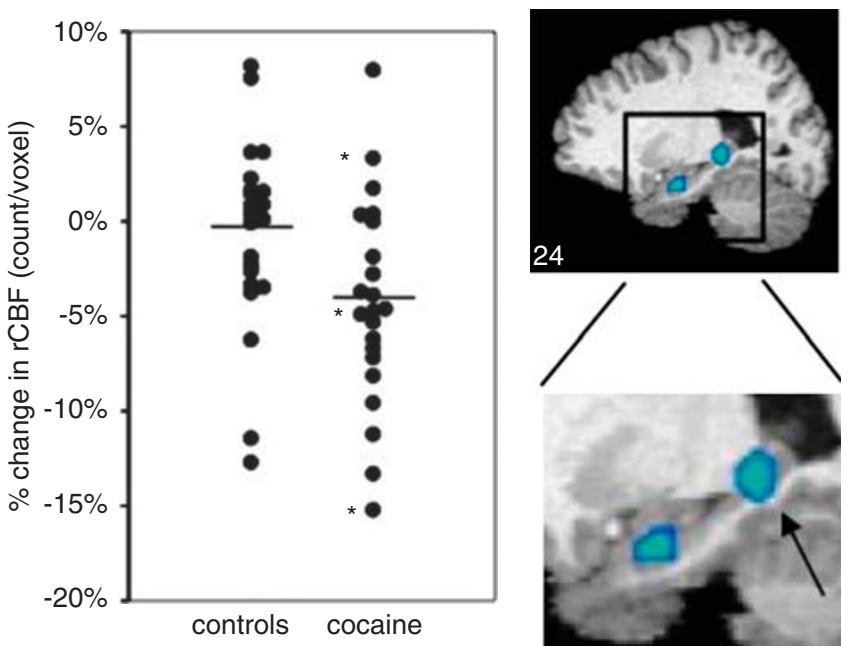

Figure 3 Counts per voxel in the region of the left posterior hippocampus in control and cocaine-addicted subjects after physostigmine infusion relative to saline infusion. Images provide sagittal view $(X$ axis -24$)$ of posterior hippocampus (arrow) and amygdala in patients after physostigmine (*non-smokers in cocaine-addicted group).

(overlapping substantia nigra and ventral tegmentum) and areas in bilateral thalamus (decreases).

Between-group comparisons (Figure 4, bottom panel) showed relative group differences in right anterior insula and left posterior cingulate. This posterior cingulate region is nearly identical to that seen in the between-group physostigmine comparison. Although scopolamine-induced large decreases in bilateral thalamic $\mathrm{rCBF}$, there were no significant differences between groups. Further analyses of
Table 3 Percent Change of Regional Cerebral Blood Flow (rCBF) in Selected Regions of Interest After Physostigmine or Scopolamine Compared with Saline

\begin{tabular}{|c|c|c|c|c|c|c|}
\hline \multirow[t]{2}{*}{$\begin{array}{l}\text { Regions of interest } \\
\text { Physostigmine vs saline }\end{array}$} & \multicolumn{2}{|c|}{$\begin{array}{l}\text { Controls } \\
(n=22)\end{array}$} & \multicolumn{3}{|c|}{$\begin{array}{l}\text { Cocaine addicted } \\
\qquad(n=22)\end{array}$} & \multirow[t]{2}{*}{$p$-value ${ }^{a}$} \\
\hline & Mean & SD & Mean & & SD & \\
\hline Left posterior hippocampus ${ }^{b}$ & -0.7 & 5.1 & -4.3 & $\downarrow$ & 5.5 & 0.027 \\
\hline Left amygdala $^{\mathrm{b}}$ & -1.2 & 6.6 & -5.3 & $\downarrow$ & 5.1 & 0.027 \\
\hline Right posterior insula ${ }^{b}$ & -0.6 & 4.5 & 3.3 & $\uparrow$ & 3.1 & 0.005 \\
\hline Right DLPFC & $-3.1 \downarrow$ & $\downarrow 3.1$ & 0 & & 3.2 & 0.005 \\
\hline \multirow[t]{2}{*}{ Scopolamine vs saline } & \multicolumn{2}{|c|}{$(n=20)$} & \multicolumn{3}{|c|}{$(n=23)$} & \\
\hline & Mean & SD & Mean & & SD & \\
\hline Left posterior hippocampus $^{b}$ & -0.2 & 5.1 & -3.4 & $\downarrow$ & 3.5 & 0.027 \\
\hline Midbrain ${ }^{b}$ & -0.5 & 5.3 & -4.3 & $\downarrow$ & 5.1 & 0.027 \\
\hline Left posterior cingulate $^{c}$ & $4.3 \uparrow$ & $\uparrow 4.4$ & -0.4 & & 5.7 & 0.01 \\
\hline Right anterior insula ${ }^{d}$ & -1.5 & 3.9 & 2.2 & $\uparrow$ & 3.5 & 0.005 \\
\hline
\end{tabular}

$\uparrow \downarrow$ direction of rCBF change in identified cluster.

${ }^{a}$ Adjusted to maintain false discovery rate (Benjamini and Hochberg, 1995).

bDerived from patient group (middle panel, Figure I and 3).

'Derived from control group (top panel, Figure I and 3).

dDerived from patient vs control group (bottom panel, Figure 3).

selected SPM-derived clusters showed a significant difference between groups in left posterior hippocampus $(p=0.027)$ and midbrain $(p=0.027)$, and left posterior cingulate $(p=0.01)$ and right anterior insula $(p=0.005)$ (Table 3$)$. 

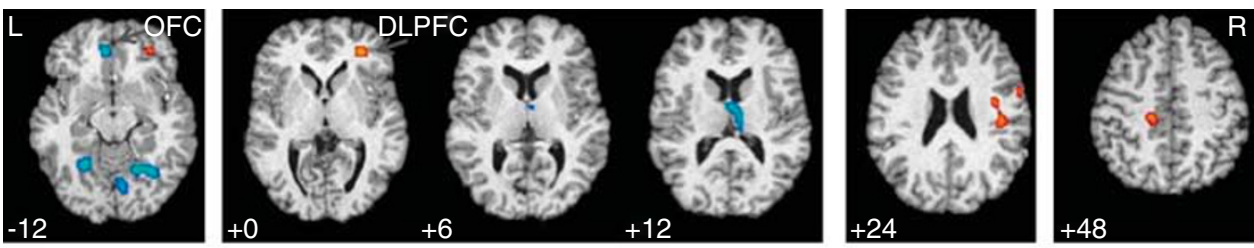

Cocaine-addicted
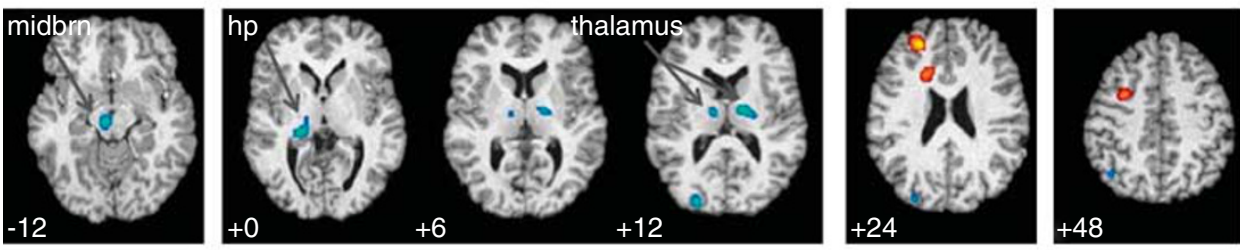

Cocaine-addicted vs. controls following scopolamine
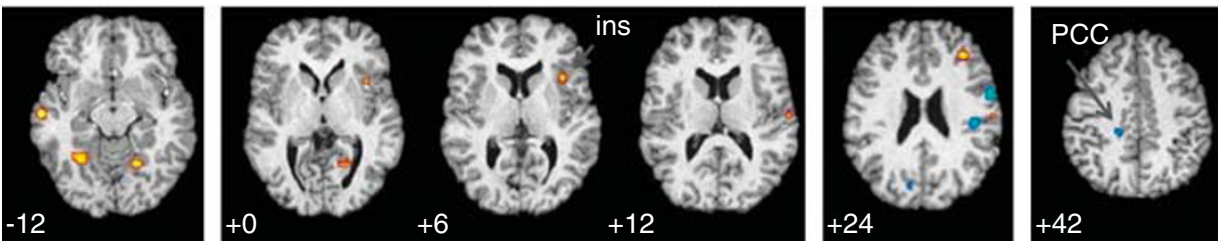

Figure 4 Regional cerebral blood flow ( $\mathrm{rCBF}$ ) changes in response to scopolamine relative to saline $(p<0.005)$ in 20 control (top panel) and 23 cocaineaddicted (middle panel) subjects. In upper and middle panels, yellow areas reveal voxels with increased rCBF after scopolamine relative to saline and blue areas reveal voxels with decreased rCBF after scopolamine relative to saline. Bottom panel displays comparison between cocaine-addicted (scopolamine - saline) and control (scopolamine — saline) subjects. Yellow areas display voxels with greater rCBF to scopolamine in patients relative to controls; blue areas are voxels with decreased rCBF response in patients relative to controls. $M N I$ coordinates ( $Z$ axis) noted at the bottom left of each image. $L=$ left; $R=$ right; $O F C=$ orbitofrontal cortex; $D L P F C=$ dorsolateral prefrontal cortex; midbrn $=$ midbrain; $h p=$ hippocampus; ins =insula; PCC $=$ posterior cingulate cortex. See Supplement 4 (controls), Supplement 5 (cocaine addicted), and Supplement 6 (comparison images) for all transverse images.

\section{Subjective Response}

Subjective Symptom Inventory. There were no significant baseline-group differences in subjective symptoms. Of the 20 subjective symptoms, physostigmine only significantly increased dry mouth relative to saline, presumably because of the glycopyrrulate (Table 5). Scopolamine increased symptoms typically associated with anticholinergic medications, including dry mouth, blurred vision, dizziness, and drowsiness. There were no significant differences between groups.

Brief Symptom Inventory. Scores showed minimal changes after these probes (Table 6). Only somatization after scopolamine in controls increased post-relative to preinfusion ( $p<0.005$, unadjusted). Between-group comparisons revealed only relative increases in somatization and global severity index in control $(p<0.05)$ and decreases in depression in cocaine-addicted $(p<0.05)$ subjects.

Blood pressure and pulse. There were no significant (multimeasure unadjusted) between-group differences in systolic or diastolic blood pressure or heart rate after any of the three infusions (Table 7). In controls, there was a significant (unadjusted) increase in heart rate after saline $(p<0.042)$ and decreases in heart rate after both physostigmine $(p<0.0004)$ and scopolamine $(p<0.0001)$. In cocaine-addicted subjects, an increase in diastolic blood pressure was observed after saline and a decrease in heart rate after scopolamine $(p<0.006)$.

\section{Clinical Variables vs rCBF}

To assess whether the amount of cocaine or nicotine use impacted image data, correlation analyses (unadjusted $p<0.05$ ) were performed on clinically relevant clusters, as defined by differences after physostigmine or scopolamine, and cocaine (lifetime days used, lifetime amount used, days used in earlier 90 days) and nicotine (lifetime pack years, cigarettes per day at time of assessment) use variables. There were no significant correlations between cocaine use variables and the eight selected regions of interest. Cigarette lifetime pack years was associated (unadjusted $p$-value) with $\mathrm{rCBF}$ in right posterior $(r=0.45, \mathrm{df}=21, p=0.035)$ and anterior insula $(r=-0.57, \mathrm{df}=21, p=0.006)$. Cigarettes/ day was significantly associated with $\mathrm{rCBF}$ in right anterior insula $(r=-0.63, \mathrm{df}=21, p=0.002)$.

\section{DISCUSSION}

Cocaine-addicted subjects differed from controls in their neural response to cholinergic probes in discrete limbic regions, including hippocampus, amygdala, and insula. 
Table 4 Brain Regions Demonstrating Increased and Decreased ( $p<0.005)$ Regional Cerebral Blood Flow (rCBF) After Scopolamine Compared with Saline in Healthy Controls and Cocaine-Dependent Subjects

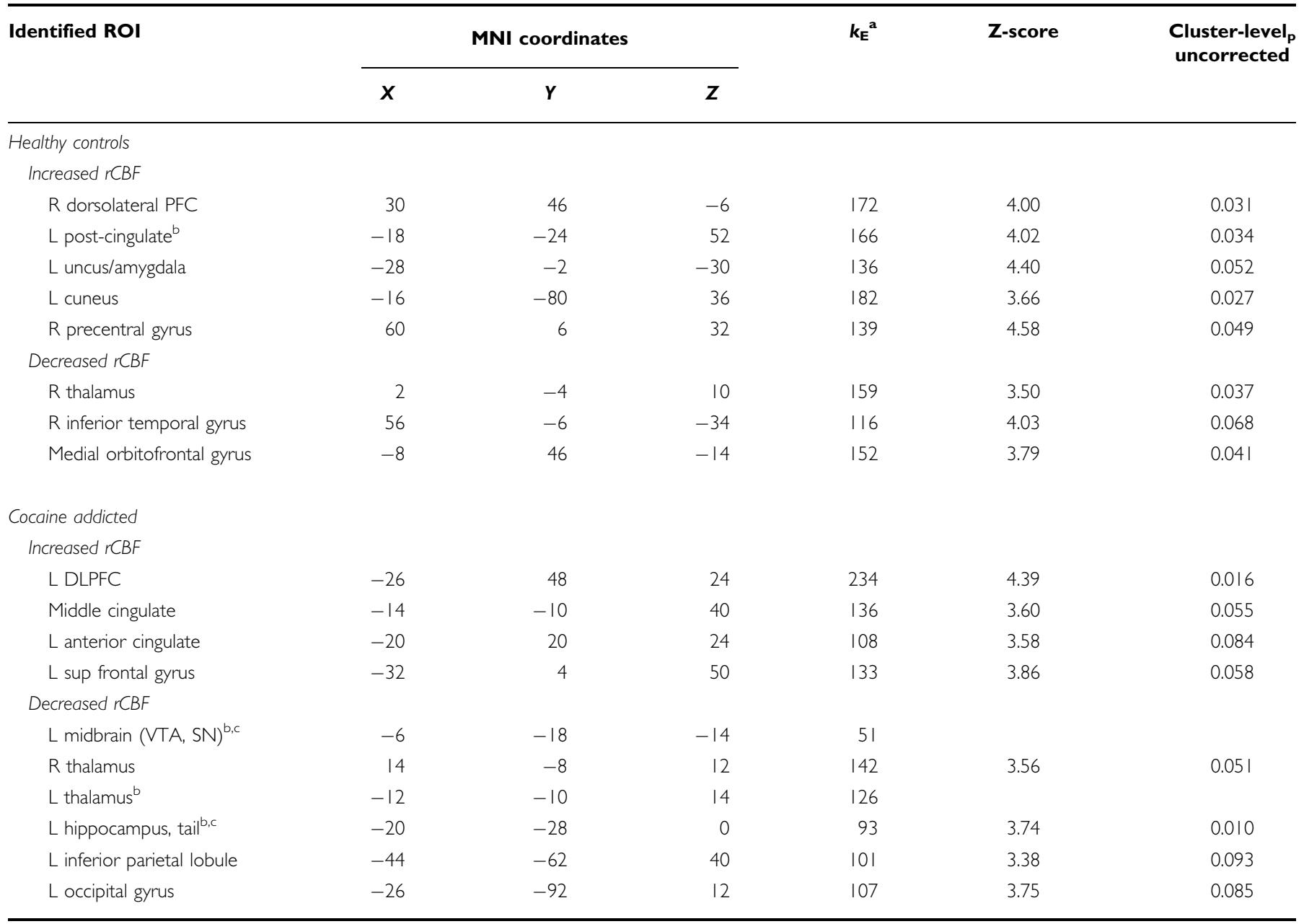

${ }^{\mathrm{a} C}$ Cluster size.

${ }^{b}$ Regions of interest considered in Table 2 and in covariate analysis.

'Three regions defined as single cluster, providing a single $p$-value. The cluster was divided into three regional components, based on anatomic boundaries, for subsequent ROI analyses.

These regions are important in the learning and memory of drug cues and associated craving. Other relevant responding regions included midbrain (including ventral tegmentum), DLPFC, orbitofrontal cortex, posterior cingulate, and middle temporal gyrus. These findings suggest a disruption in cholinergic receptor systems, particularly mAChRs, in abstinent cocaine-addicted subjects compared with healthy controls similar in age, sex, and race. Although the multiple sources of cholinergic afferents and the presence of both inhibitory and excitatory $\mathrm{mACh} / \mathrm{nACh}$ receptor subtypes currently prohibit an integrated, cohesive explanation for the regional differences observed, our findings reveal a significant alteration in cholinergic mechanisms in cocaineaddicted subjects.

\section{Muscarinic and Nicotinic Cholinergic Probes}

We found a mix of both increased and decreased rCBF after both physostigmine and scopolamine. Earlier studies suggesting that physostigmine did not significantly alter rCBF in healthy controls suffered from subthreshold doses of physostigmine (Blin et al, 1994b; Geaney et al, 1990) or relatively insensitive measures of cerebral blood flow (Gustafson et al, 1987). Although Blin et al (1997, 1994a) used a maintenance physostigmine and bolus scopolamine dosing strategy somewhat similar to ours, this group reported consistent decreases in regional glucose consumption after physostigmine and generalized increases with scopolamine in healthy controls. The most striking difference in methodology is our use of functionally derived ROIs compared with Blin et al's use of larger anatomically derived ROIs, allowing us substantially more rigor in isolating specific areas of neural change.

The mix of increased and decreased rCBF after either physostigmine or scopolamine indicates that the use of these two probes, while affecting relatively specific brain regions with high concentrations of ACh terminals, do not induce straightforward changes in rCBF. In addition, some regions with particularly high concentrations of cholinergic receptors (ie amygdala, hippocampus) showed no or limited rCBF changes in control subjects after either probe. These findings emphasize the difficulty in isolating specific 
Table 5 Comparison Between Controls and Cocaine-Addicted Subjects in Change in Symptom Inventory After Saline, Physostigmine, and Scopolamine Infusions

Symptom

\begin{tabular}{|c|c|c|c|c|c|c|c|c|c|}
\hline & & & \\
\hline & $\begin{array}{l}\text { Control } \\
(n=21)\end{array}$ & $\begin{array}{l}\text { Cocaine } \\
(n=22)\end{array}$ & $p$-value ${ }^{a}$ & $\begin{array}{l}\text { Control } \\
(n=18)\end{array}$ & $\begin{array}{l}\text { Cocaine } \\
(n=22)\end{array}$ & $p$-value ${ }^{a}$ & $\begin{array}{l}\text { Control } \\
(n=20)\end{array}$ & $\begin{array}{l}\text { Cocaine } \\
(n=23)\end{array}$ & $p$-value ${ }^{a}$ \\
\hline Heart racing & $0.00 \pm 0.00$ & $0.10 \pm 0.45$ & 0.55 & $0.27 \pm 0.73$ & $0.33 \pm 1.03$ & 0.88 & $0.17 \pm 0.71$ & $0.05 \pm 0.22$ & 0.69 \\
\hline Muscle twitching & $0.00 \pm 0.0$ & $0.26 \pm 0.55$ & 0.53 & $0.11 \pm 0.32$ & $0.50 \pm 1.30$ & 0.53 & $0.11 \pm 0.32$ & $0.24 \pm 0.54$ & 0.61 \\
\hline Shakiness & $0.00 \pm 0.0$ & $0.10 \pm 0.31$ & 0.53 & $0.00 \pm 0.0$ & $0.06 \pm 0.24$ & 0.55 & $0.00 \pm 0.0$ & $0.00 \pm 0.0$ & - \\
\hline Stomach cramps & $0.00 \pm 0.0$ & $0.05 \pm 0.22$ & 0.55 & $0.00 \pm 0.0$ & $0.17 \pm 0.51$ & 0.53 & $0.00 \pm 0.0$ & $0.00 \pm 0.0$ & - \\
\hline Dry mouth & $0.20 \pm 0.41$ & $0.40 \pm 0.75$ & 0.55 & $1.32 \pm 1.34$ & $1.61 \pm 1.54^{b}$ & 0.73 & $2.50 \pm\left. 1.5\right|^{c}$ & $2.7 \mid \pm 1.7 I^{c}$ & 0.97 \\
\hline Decreased sweating & $0.00 \pm 0.0$ & $0.00 \pm 0.0$ & - & $0.00 \pm 0.0$ & $0.00 \pm 0.0$ & - & $0.06 \pm 0.24$ & $0.00 \pm 0.0$ & 0.55 \\
\hline Eye irritation & $0.05 \pm 0.22$ & $0.00 \pm 0.0$ & 0.55 & $0.26 \pm 0.56$ & $0.28 \pm 0.96$ & 0.99 & $0.17 \pm 0.51$ & $0.10 \pm 0.44$ & 0.78 \\
\hline Eye dryness & $0.20 \pm 0.52$ & $0.00 \pm 0.0$ & 0.53 & $0.63 \pm 1.07$ & $0.11 \pm 0.32$ & 0.53 & $0.72 \pm 0.13$ & $0.24 \pm 0.70$ & 0.53 \\
\hline Sadness & $0.00 \pm 0.0$ & $0.00 \pm 0.0$ & - & $0.00 \pm 0.0$ & $0.28 \pm 0.96$ & 0.53 & $0.00 \pm 0.0$ & $0.00 \pm 0.0$ & - \\
\hline Confused & $0.00 \pm 0.0$ & $0.10 \pm 0.31$ & 0.53 & $0.00 \pm 0.0$ & $0.22 \pm 0.94$ & 0.55 & $0.00 \pm 0.0$ & $0.10 \pm 0.30$ & 0.53 \\
\hline Dizzy & $0.00 \pm 0.0$ & $0.00 \pm 0.0$ & - & $0.32 \pm 0.58$ & $0.44 \pm 1.04$ & 0.78 & $1.00 \pm 1.24$ & $0.43 \pm 0.51^{d}$ & 0.53 \\
\hline Anxious & $0.20 \pm 0.70$ & $0.40 \pm 1.10$ & 0.71 & $0.11 \pm 0.32$ & $0.33 \pm 0.97$ & 0.57 & $0.28 \pm 0.75$ & $0.20 \pm 0.52$ & 0.80 \\
\hline Drowsiness & $0.25 \pm 0.44$ & $0.70 \pm 1.13$ & 0.53 & $0.37 \pm 0.68$ & $1.00 \pm 1.50$ & 0.69 & $1.61 \pm 1.61^{b}$ & $2.19 \pm 1.91^{\mathrm{d}}$ & 0.72 \\
\hline Restlessness & $0.05 \pm 0.22$ & $0.45 \pm 1.23$ & 0.53 & $0.16 \pm 0.38$ & $0.28 \pm 0.96$ & 0.78 & $0.39 \pm 0.98$ & $0.38 \pm 0.59$ & 0.99 \\
\hline
\end{tabular}

ap-values adjusted to maintain false discovery rate.

b Increase after physostigmine/scopolamine relative to saline $(p<0.05)$.

Increase after physostigmine/scopolamine relative to saline $(p<0.005)$.

Increase after physostigmine/scopolamine relative to saline $(p<0.01)$.
Physostigmine [mean (SD)]

Table 6 Comparison Between Controls and Cocaine-Addicted Subjects in Change in BSI After Saline, Physostigmine, and Scopolamine Infusions

\begin{tabular}{|c|c|c|c|c|c|c|c|c|c|}
\hline \multirow[t]{2}{*}{ Symptoms } & \multicolumn{3}{|c|}{ Saline [mean (SD)] } & \multicolumn{3}{|c|}{ Physostigmine [mean (SD)] } & \multicolumn{3}{|c|}{ Scopolamine [mean (SD)] } \\
\hline & $\begin{array}{l}\text { Control } \\
(n=22)\end{array}$ & $\begin{array}{l}\text { Cocaine } \\
(n=23)\end{array}$ & $p$-value ${ }^{a}$ & $\begin{array}{l}\text { Control } \\
(n=22)\end{array}$ & $\begin{array}{l}\text { Cocaine } \\
(n=22)\end{array}$ & $p$-value ${ }^{a}$ & $\begin{array}{l}\text { Control } \\
(n=20)\end{array}$ & $\begin{array}{l}\text { Cocaine } \\
(n=23)\end{array}$ & $p$-value ${ }^{\text {a }}$ \\
\hline Somatization & $0.006 \pm 0.08$ & $0.013 \pm 0.06$ & 0.39 & $0.045 \pm 0.13$ & $0.103 \pm 0.43$ & 0.543 & $0.186 \pm 0.26$ & $0.031 \pm 0.11$ & 0.013 \\
\hline Obsessive-compulsive & $-0.008 \pm 0.04$ & $0.023 \pm 0.14$ & 0.629 & $0.000 \pm 0.09$ & $-0.060 \pm 0.22$ & 0.228 & $0.025 \pm 0.23$ & $-0.007 \pm 0.20$ & 0.623 \\
\hline Anxiety & $-0.008 \pm 0.04$ & $0.046 \pm 0.11$ & 0.113 & $0.008 \pm 0.11$ & $0.015 \pm 0.19$ & 0.879 & $0.009 \pm 0.09$ & $-0.036 \pm 0.23$ & 0.410 \\
\hline Hostility & $0.000 \pm 0.00$ & $0.045 \pm 0.11$ & 0.050 & $0.000 \pm 0.00$ & $0.027 \pm 0.17$ & 0.447 & $-0.010 \pm 0.05$ & $-0.026 \pm 0.07$ & 0.377 \\
\hline Phobic anxiety & $0.00 \pm 0.00$ & $0.018 \pm 0.06$ & 0.155 & $0.000 \pm 0.00$ & $0.000 \pm 11$ & 0.999 & $0.000 \pm 0.00$ & $0.026 \pm 0.07$ & 0.098 \\
\hline Paranoid ideation & $0.000 \pm 0.00$ & $0.091 \pm 0.33$ & 0.197 & $-0.036 \pm 0.13$ & $0.027 \pm 0.16$ & 0.151 & $-0.020 \pm 0.09$ & $-0.000 \pm 0.15$ & 0.601 \\
\hline Psychoticism & $-0.027 \pm 0.13$ & $0.009 \pm 0.14$ & 0.661 & $0.000 \pm 0.00$ & $0.045 \pm 0.14$ & 0.127 & $-0.030 \pm 0.10$ & $-0.017 \pm 0.10$ & 0.684 \\
\hline
\end{tabular}

a $p$-values uncorrected for multiple comparisons.

bIncrease post-infusion relative to pre-infusion. 
Table 7 Comparison Between Controls and Cocaine-Addicted Subjects in Change in Blood Pressure and Heart Rate After Saline, Physostigmine, and Scopolamine Infusions

\begin{tabular}{|c|c|c|c|c|c|c|c|c|c|}
\hline & \multicolumn{3}{|c|}{ Saline [mean (SD)] } & \multicolumn{3}{|c|}{ Physostigmine [mean (SD)] } & \multicolumn{3}{|c|}{ Scopolamine [mean (SD)] } \\
\hline & Controls & Cocaine & $p$-value ${ }^{a}$ & Control & $\begin{array}{l}\text { Cocaine } \\
\text { addicted }\end{array}$ & $p$-value ${ }^{a}$ & Control & $\begin{array}{l}\text { Cocaine } \\
\text { addicted }\end{array}$ & $p$-value ${ }^{a}$ \\
\hline$\Delta$ Heart rate & $-2.36 \pm 5.1$ & $-2.04 \pm 6.7$ & 0.93 & $-5.62 \pm 6.0$ & $-3.32 \pm 8.1$ & 0.93 & $-8.55 \pm 7.1$ & $-4.35 \pm 6.9$ & 0.50 \\
\hline$\Delta$ Systolic BP & $0.55 \pm 7.5$ & $1.13 \pm 8.7$ & 0.93 & $1.67 \pm 9.4$ & $1.90 \pm 8.1$ & 0.93 & $-2.65 \pm 6.9$ & $-1.87 \pm 7.4$ & 0.93 \\
\hline$\Delta$ Diastolic BP & $0.73 \pm 4.7$ & $2.8 \pm 4.4$ & 0.62 & $1.19 \pm 5.6$ & $2.55 \pm 5.6$ & 0.93 & $0.95 \pm 4.8$ & $1.39 \pm 4.9$ & 0.93 \\
\hline
\end{tabular}

${ }^{a} p$-values adjusted to maintain false discovery rate.

cholinergic receptor systems in vivo, even using probes specific to the cholinergic system, and is likely due to the mix of inhibitory and excitatory nicotinic and muscarinic subtypes and the complex interplay between these inputs (Zhou et al, 2003). For example, an equal distribution of excitatory and inhibitory cholinergic receptors in a brain region would result in a relative absence of $\mathrm{rCBF}$ change after physostigmine, as the two opposing directional changes would effectively cancel each other out. As detailed below, however, a relative increase or decrease in either inhibitory or excitatory cholinergic receptors after chronic cocaine use could result in a net change in $\mathrm{rCBF}$.

A combination of inhibitory and excitatory receptor subtypes could also underlie the apparent unidirectional changes in rCBF that occasionally occurred in a discrete region after physostigmine and scopolamine. For example, the left posterior hippocampus was decreased in the cocaine-addicted group in response to both medications. We had predicted that the use of a cholinergic $\mathrm{mAChR}$ and nAChR agonist (physostigmine) and mAChR antagonist (scopolamine) would push rCBF activation in opposite directions and allow the delineation between mAChR and $\mathrm{nAChR}$ systems. A possible explanation of our findings may lie in the prevalence of both post-synaptic excitatory $M_{1}$ receptors and $M_{2}$ inhibitory pre-synaptic autoreceptors in the hippocampus. A relative decrease in $M_{1}$ excitatory hippocampal receptor number or affinity after chronic cocaine use would produce an $\mathrm{rCBF}$ decrease after the administration of both physostigmine (because of attenuated stimulation of excitatory receptors relative to inhibitory autoreceptors) and scopolamine (because of more effective blockade of fewer excitatory receptors), consistent with our findings. Similarly, a relative increase in $\mathrm{M}_{2}$ hippocampal receptors in cocaine-addicted subjects would induce a decrease in $\mathrm{rCBF}$ after the administration of both physostigmine (because of relatively greater ACh stimulation of inhibitory autoreceptors) and scopolamine (because of a more ineffective blockade of increased inhibitory autoreceptors).

\section{Regions of Interest}

One of the most discrete findings, and of critical relevance to the addictive process, was the group difference observed in the posterior hippocampus in a cluster that includes the hippocampal tail, after both physostigmine and scopolamine. Using multidirectional high-resolution MRI images in the rat, cat, dog, and human Sasaki et al (2004) concluded that the hippocampal tail in the human brain is homologous to the non-primate dorsal hippocampus. The dorsal hippocampus is required for contextual conditioning during cocaine administration. For example, lesions of the dorsal hippocampus disrupt both the acquisition and expression of cocaine conditioned place preference in the rodent (Meyers et al, 2006) and Crombag et al (2008) have posited a function for a serial relationship between the dorsal hippocampus, basolateral amygdala, dorsal striatum, and dorsal medial PFC in context-induced drug reinstatement. Contextual learning processes are mediated, at least in part, by cholinergic receptors and the hippocampus has among the highest concentrations of $\mathrm{ACh}$ in the CNS. Hippocampal ACh receptors are primarily muscarinic; drugs that block mAChRs, such as scopolamine, impair the encoding of new information (Hasselmo, 1995) and hippocampal $M_{2}$ knock-out mice show a dramatic decrease in long-term potentiation (Seeger et al, 2004). Given the dopaminergic influence on hippocampal cholinergic output (Imperato et al, 1993b), it is reasonable to assume that chronic cocaine use could alter hippocampal cholinergic receptors. In fact, extracellular and turnover rates of hippocampal ACh are increased after acute cocaine administration (Imperato et al, 1993a; Imperato et al, 1996; Robinson and Hambrecht, 1988; Smith et al, 2004b) and 5 days of cocaine administration significantly decrease hippocampal mACh receptor binding (Zeigler et al, 1991). Thus, the extant literature would suggest that the observed hippocampal alterations in cocaine-addicted subjects could be a result of chronic cocaine use and that disruptions in dorsal hippocampal cholinergic regulation could alter the ability of cocaine-addicted subjects to extinguish cocainecued learning. Enhancement of hippocampus neurogenesis by a cholinergic agonist (Kotani et al, 2008), a process inhibited by chronic cocaine administration (Noonan et al, 2008; Yamaguchi et al, 2004), also points to putative function of the cholinergic system in cocaine-induced hippocampal functioning.

Other relevant regions of differing $\mathrm{rCBF}$ responses included the insular cortex, ACC, and DLPFC, with the insular cortex and DLPFC reaching our statistical threshold for differences between groups. Unlike the hippocampal $\mathrm{ACh}$ projections, which arise primarily from the medial septum-vertical diagonal band of Broca (Ch1 and Ch2), the cortex (and amygdala) receives cholinergic projections mainly from the nucleus basalis of Meynert (Ch4) 
(Mesulam, 1996). All of these regions have been implicated in the craving response to cocaine. The response of the insula was of particular interest. The cocaine-addicted group, relative to controls, showed an increased $\mathrm{rCBF}$ response in the posterior insula after physostigmine and the anterior insula after scopolamine. The insula, particularly the anterior insula, is preferentially involved in the evaluative, experiential, or expressive aspects of internally generated emotions (Craig, 2003; Reiman et al, 1997). The insula is frequently noted to be active during cocaine craving (Bonson et al, 2002; Garavan et al, 2000; Kilts et al, 2001) and lesions of the insula, particularly on the right side of the brain, has been associated with the dissolution of craving in nicotine-addicted subjects (Naqvi et al, 2007). Right insular activation during a two-choice prediction task has also been associated with relapse in methamphetaminedependent subjects (Paulus et al, 2005). The DLPFC, a key area for working memory and also frequently activated during cocaine craving (Grant et al, 1996; Maas et al, 1998), also showed $\mathrm{rCBF}$ differences between groups after both infusions.

A rather large area of the left MTG showed increased rCBF after physostigmine in cocaine-addicted subjects relative to controls. Given the connections of the MTG with other temporal lobe structures, including the hippocampus, a function for this region in aspects of declarative memory has been suggested. However, the relationship of the MTG to cocaine addiction is not immediately apparent. Nevertheless, a number of earlier investigators have identified alterations in the MTG in cocaine-addicted populations under a variety of paradigms. Risinger et al (2005) found significant correlations between cocaine-induced anxiety and MTG activation, Paulus et al (2005) reported a correlation between relapse and MTG activation in methamphetamine-dependent subjects, and Kosten et al (2006) noted a relationship between MTG activation during cue-induced craving and treatment outcome. Thus, the MTG may have functions relevant to cocaine addiction distinct from its function in declarative memory.

A region of the left posterior cingulate cortex (PCC) was of particular interest. PCC activation has been associated with craving ( $\mathrm{Li}$ et al, 2005) or relapse risk (Paulus et al, 2005) in both cocaine- and methamphetamine-addicted subjects. The dorsal PCC changes identified a similar location of decreased rCBF after both physostigmine $(-16,-26,50 ; 251)$ (Figure 2, bottom panel) and scopolamine $(-18,-26,54 ; 131)$ (Figure 4 , bottom panel).

Co-morbid nicotine dependence. All but three of our cocaine-addicted subjects were smokers, and all but six of the controls were non-smokers; five of these six controls were very light smokers. This confound generally plagues most clinical laboratory research of substance abusers, as most drug-dependent patients smoke and most healthy volunteers without medical or psychological morbidity do not. Nevertheless, there are several reasons supporting the function of cocaine use, as opposed to just nicotine use, in our findings.

First, scopolamine, a mAChR receptor antagonist, showed significant group differences. This probe would not have been expected to be particularly sensitive to nicotineinduced changes acting directly on nAChRs. In addiction, cocaine, unlike nicotine, has been shown to bind directly with mAChRs (Flynn et al, 1992a; Sharkey et al, 1988a) and cocaine administration alters mAChRs in preclinical models (Lipton et al, 1995; Sousa et al, 1999; Zeigler et al, 1991). Second, Brody et al (2006) has observed that nAChRs remain occupied by nicotine for several hours after smoking in nicotine-dependent subjects. As our nicotine-dependent subjects smoked a cigarette $2 \mathrm{~h}$ before infusion, their nAChRs may have been relatively resilient to the effects of physostigmine-induced elevations in ACh and thus reflect primarily mAChR systems. Third, our small sample of cocaine-addicted non-smokers and controls smokers did not suggest a nicotine-relevant effect (Figure 3). Finally, a recent study by Easwaramoorthy et al (2007) reveals that physostigmine infusion, in the absence of an additional infusion of ACh, does not alter $\alpha_{4} \beta_{2}$ nAChR binding. On the other hand, Carson et al (1998) found that the administration of physostigmine to nonhuman primates produced a $35 \%$ decrease in $\mathrm{mAChR}$ cortical binding.

That being said, nicotine itself may alter mAChRs. For instance, acute administration studies show that nicotine directly alters $\mathrm{rCBF}$ in regions observed after both physostigmine and scopolamine infusion in this study, including the hippocampus, anterior and posterior cingulate, and insula (Domino et al, 2000a; Domino et al, 2000b; Rose et al, 2003; Zubieta et al, 2005). The relevance of nicotine dependence to our findings would best be answered by a similar study in healthy controls with nicotine dependence. Although an assessment of cocaineaddicted subjects without nicotine dependence might be of academic interest, given the high co-morbidity of nicotine and cocaine dependence (Kalman et al, 2005), such a study would have little clinical relevance and may miss a critical interactive effect between nicotine and cocaine.

Other strengths and weaknesses. A major strength of our study was the use of age-, sex-, and race-similar cocaineaddicted and control subjects. Cocaine-addicted subjects did not have other active drug use disorders (except nicotine) and were studied during a defined period of verified abstinence, thus avoiding the rapid fluctuations in neural activity that occur during the first few days of cocaine abstinence as well as the more gradual changes that may develop with extended abstinence. Menstrual cycles were not controlled because of the several days required to conduct multiple infusions. Although central cholinergic neurons can be altered by estrogen (Smith et al, 2001), human studies show that nAChRs (containing $b_{2}$-subunits) do not change over the menstrual cycle (Cosgrove et al, 2007). Both infusions provoked relatively specific rCBF responses with minimal, if any, adverse effects. Although physostigmine is relatively non-specific, most likely reflecting both pre- and post-synaptic cortical cholinergic transmission (Bohnen and Frey, 2007), it does reduce $40-50 \%$ of AChE activity in healthy volunteers (Koeppe et al, 1997). Neither an age nor a gender effect of cortical AChE activity is present in healthy controls (Kuhl et al, 1999; Namba et al, 1999), making physostigmine a relatively stable measure to compare groups. 
Limits of spatial resolution and the ability to only determine relative measures of limbic activation are inherent in our SPECT methodology and camera. It should also be noted that the SPECT technique used assessed relative (to whole brain), not absolute, rCBF differences between groups. Although volumetric reductions have been reported in cocaine-addicted subjects (Bartzokis et al, 2002; Franklin et al, 2002; Lim et al, 2002; Matochik et al, 2003) relative to controls, no discrete structural lesions (by MRI) were observed in any of the subjects in this study. However, we cannot rule out the possibility that regions of muted rCBF responses observed in cocaine-addicted subjects resulted from neuronal loss. Further, areas differing between groups after the pharmacologic probes could actually be abnormal at baseline. However, regions earlier reported to show baseline differences in rCBF (Adinoff et al, 2006) generally differ from those identified between cocaine-addicted and control subjects in our data.

Finally, there are inherent errors in spatial normalization for all functional imaging techniques, thus limiting the precision of our anatomic identifications. Further, SPECT imaging is limited to a reconstructed resolution of about $6 \mathrm{~mm}$, and for our analyses, this was further smoothed to $10 \mathrm{~mm}$, and suffers from partial volume effects as well. Thus, anatomic labeling of significant clusters should be interpreted cautiously. It is also true that there are reports of inherent variability over time in rCBF measures (modest in healthy controls, but less well studied in patient populations). The effects are generally random among subjects, but it cannot be entirely ruled out that some of our observations are affected by this inherent day-to-day variability in $\mathrm{rCBF}$.

\section{CONCLUSION}

This is, to our knowledge, the first human study to reveal differences in central cholinergic functioning of cocaineaddicted subjects compared with healthy controls. Furthermore, these differences are in regions known to be heavily cholinergically innervated and highly relevant to the addictive process. Although $\mathrm{rCBF}$ with SPECT is highly useful in eliciting the integrated CNS response to a receptorspecific pharmacologic challenge, a variety of highly specific muscarinic and nAChR imaging agents will be necessary in delineating specific receptor alterations in cocaine-addicted subjects. Our work provides a sound rationale for investigating specific $\mathrm{nAChR}$ and $\mathrm{mAChR}$ changes as well as cholinergic pharmacologic approaches in the addictions.

\section{ACKNOWLEDGEMENTS}

We thank the staff of the Substance Abuse Team at the VA North Texas Health Care System, Homeward Bound, and the Nexus Recovery Center for their support in the screening and recruitment of study subjects. Dr Adinoff had full access to all of the data in the study and takes responsibility for the integrity of the data and the accuracy of the data analysis. This study was funded by NIH DA11434 and supported by the VA North Texas Health Care System. Ceretec (HMPAO) was generously supplied by GE Healthcare.

\section{DISCLOSURE}

Bryon Adinoff has received grant/research support from the NIAAA, NIDA, Department of Veterans Affairs. He has served as Consultant: Pain Insights, medical malpractice consultant to Conroy, Simberg, Ganon, Krevans \& Abel, PA; as advisor to GlaxoSmithKline; as legal consultant to The Hershewe Law Firm, PC; and has received Honoraria: CME, from the Temple University, Texas, Department of State Health Services in 2006. He has served as legal consultant to Phillips Lytle LLP for GSK; as advisor to GlaxoSmithKline; as medical malpractice consultant to The Hershewe Law Firm, PC; and has received Honoraria: from American Academy of Addiction Psychiatry, Medical University of South Carolina in 2007. He also served as medical malpractice consultant to Simon Pissante PC; as advisor to Teva Pharmaceutical Industries; as medical malpractice consultant to Shook, Hardy \& Bacon LLP for tobacco companies; and has received Honoraria: from American Academy of Addiction Psychiatry, University of New Mexico in 2008. Michael D Devous has served on the Scientific Advisory Board of AVID Radiopharmaceuticals and also received research support from AVID Radiopharmaceuticals and Alseres. The remaining authors declare no conflict of interest.

\section{REFERENCES}

Adinoff B, Rilling LM, Williams MJ, Schreffler ER, Schepis TY, Rosvall $\mathrm{T}$ et al (2007). Impulsivity, neural deficits, and the addictions: the 'Oops' factor in relapse. J Addict Dis 26(Suppl 1): 25-39.

Adinoff B, Williams MJ, Best SE, Harris TS, Chandler P, Devous Sr MD (2006). Sex differences in medial and lateral orbitofrontal cortex hypoperfusion in cocaine-dependent men and women. Gend Med 3: 206-222.

Ahveninen J, Tiitinen H, Hirvonen J, Pekkonen E, Huttunen J, Kaakkola S et al (1999). Scopolamine augments transient auditory $40-\mathrm{hz}$ magnetic response in humans. Neurosci Lett 277: 115-118.

Bartzokis G, Beckson M, Lu PH, Edwards N, Bridge P, Mintz J (2002). Brain maturation may be arrested in chronic cocaine addicts. Biol Psychiatry 51: 605-611.

Benjamini Y, Hochberg Y (1995). Controlling the false discovery rate: a practical and powerful approach to multiple testing. $J R$ Stat Soc B 57: 289-300.

Berlanga ML, Olsen CM, Chen V, Ikegami A, Herring BE, Duvauchelle CL et al (2003). Cholinergic interneurons of the nucleus accumbens and dorsal striatum are activated by the selfadministration of cocaine. Neuroscience 120: 1149-1156.

Berlanga ML, Simpson TK, Alcantara AA (2005). Dopamine D5 receptor localization on cholinergic neurons of the rat forebrain and diencephalon: a potential neuroanatomical substrate involved in mediating dopaminergic influences on acetylcholine release. J Comp Neurol 492: 34-49.

Blin J, Ivanoiu A, Coppens A, De Volder A, Labar D, Michel C et al (1997). Cholinergic neurotransmission has different effects on cerebral glucose consumption and blood flow in young normals, aged normals, and Alzheimer's disease patients. Neuroimage 6: 335-343.

Blin J, Ray CA, Piercey MF, Bartko JJ, Mouradian MM, Chase TN (1994a). Comparison of cholinergic drug effects on regional brain glucose consumption in rats and humans by means of autoradiography and position emission tomography. Brain Res 635: 196-202. 
Blin J, Ray CA, Piercey MF, Bartko JJ, Mouradian MM, Chase TN (1994b). Comparison of cholinergic drug effects on regional brain glucose consumption in rats and humans by means of autoradiography and position emission tomography. Brain Res 635: 196-202.

Bohnen NI, Frey KA (2007). Imaging of cholinergic and monoaminergic neurochemical changes in neurodegenerative disorders. Mol Imaging Biol 9: 243-257.

Bonson KR, Grant SJ, Contoreggi CS, Links JM, Metcalfe J, Weyl HL et al (2002). Neural systems and cue-induced cocaine craving. Neuropsychopharmacology 26: 376-386.

Brody AL, Mandelkern MA, London ED, Olmstead RE, Farahi J, Scheibal D et al (2006). Cigarette smoking saturates brain alpha 4 beta 2 nicotinic acetylcholine receptors. Arch Gen Psychiatry 63: 907-915.

Carson RE, Kiesewetter DO, Jagoda E, Der MG, Herscovitch P, Eckelman WC (1998). Muscarinic cholinergic receptor measurements with [18F]FP-TZTP: control and competition studies. J Cereb Blood Flow Metab 18: 1130-1142.

Chen KC, Baxter MG, Rodefer JS (2004). Central blockade of muscarinic cholinergic receptors disrupts affective and attentional set-shifting. Eur J Neurosci 20: 1081-1088.

Clarke PB, Pert A (1985). Autoradiographic evidence for nicotine receptors on nigrostriatal and mesolimbic dopaminergic neurons. Brain Res 348: 355-358.

Consolo S, Caltavuturo C, Colli E, Recchia M, Di Chiara G (1999). Different sensitivity of in vivo acetylcholine transmission to D1 receptor stimulation in shell and core of nucleus accumbens. Neuroscience 89: 1209-1217.

Cosgrove KP, Mitsis EM, Bois F, Frohlich E, Tamagnan GD, Krantzler E et al (2007). 123I-5-IA-85380 SPECT imaging of nicotinic acetylcholine receptor availability in nonsmokers: effects of sex and menstrual phase. J Nucl Med 48: 1633-1640.

Craig AD (2003). Interoception: the sense of the physiological condition of the body. Curr Opin Neurobiol 13: 500-505.

Crespo JA, Sturm K, Saria A, Zernig G (2006). Activation of muscarinic and nicotinic acetylcholine receptors in the nucleus accumbens core is necessary for the acquisition of drug reinforcement. J Neurosci 26: 6004-6010.

Crombag HS, Bossert JM, Koya E, Shaham Y (2008). Review. Context-induced relapse to drug seeking: a review. Philos Trans $R$ Soc Lond B Biol Sci 363: 3233-3243.

de la Garza R, Johanson CE (1982). Effects of haloperidol and physostigmine on self-administration of local anesthetics. Pharmacol Biochem Behav 17: 1295-1299.

De La Garza R, Shoptaw S, Newton TF (2008). Evaluation of the cardiovascular and subjective effects of rivastigmine in combination with methamphetamine in methamphetamine-dependent human volunteers. Int J Neuropsychopharmacol 11: 729-741.

Derogatis LR, Melisaratos N (1983). The Brief Symptom Inventory: an introductory report. Psychol Med 13: 595-605.

Devous Sr MD (2002). SPECT functional brain imaging. In: Mazziotta JC, Toga AW (eds). BrainMapping: The Methods. Second edn. Academic Press: San Diego. pp 513-533.

Dick DM, Aliev F, Wang JC, Grucza RA, Schuckit M, Kuperman S et al (2008). Using dimensional models of externalizing psychopathology to aid in gene identification. Arch Gen Psychiatry 65: 310-318.

Domino EF, Minoshima S, Guthrie S, Ohl L, Ni L, Koeppe RA et al (2000a). Nicotine effects on regional cerebral blood flow in awake, resting tobacco smokers. Synapse 38: 313-321.

Domino EF, Minoshima S, Guthrie SK, Ohl L, Ni L, Koeppe RA et al (2000b). Effects of nicotine on regional cerebral glucose metabolism in awake resting tobacco smokers. Neuroscience 101: 277-282.

Easwaramoorthy B, Pichika R, Collins D, Potkin SG, Leslie FM, Mukherjee J (2007). Effect of acetylcholinesterase inhibitors on the binding of nicotinic alpha4beta2 receptor PET radiotracer,
(18)F-nifene: a measure of acetylcholine competition. Synapse 61: 29-36

Fink-Jensen A, Fedorova I, Wortwein G, Woldbye DP, Rasmussen $\mathrm{T}$, Thomsen $\mathrm{M}$ et al (2003). Role for M5 muscarinic acetylcholine receptors in cocaine addiction. J Neurosci Res 74: 91-96.

First MH, Spitzer RL, Miriam G, Williams JBW (2002). Structured Clinical Interview for DSM-IV Axis I Disorders-Patient Edition $(S C I D-I / P)$. Biometrics Research Department, New York State Psychiatric Institute: NY.

Flynn DD, Vaishnav AA, Mash DC (1992a). Interactions of cocaine with primary and secondary recognition sites on muscarinic receptors. Mol Pharmacol 41: 736-742.

Flynn DD, Vaishnav AA, Mash DC (1992b). Interactions of cocaine with primary and secondary recognition siteson muscarinic receptors. Mol Pharmacol 41: 736-742.

Franklin TR, Acton PD, Maldjian JA, Gray JD, Croft JR, Dackis CA et al (2002). Decreased gray matter concentration in the insular, orbitofrontal, cingulate, and temporal cortices of cocaine patients. Biol Psychiatry 51: 134-142.

Furey ML, Pietrini P, Alexander GE, Mentis MJ, Szczepanik J, Shetty U et al (2000). Time course of pharmacodynamic and pharmacokinetic effects of physostigmine assessed by functional brain imaging in humans. Pharmacol Biochem Behav 66: 475-481.

Garavan H, Pankiewicz J, Bloom A, Cho JK, Sperry L, Ross TJ et al (2000). Cue-induced cocaine craving: neuroanatomical specificity for drug users and drug stimuli. Am J Psychiatry 157: 1789-1798.

Geaney DP, Soper N, Shepstone BJ, Cowen PJ (1990). Effect of central cholinergic stimulation on regional cerebral blood flow in Alzheimer disease. Lancet 335: 1484-1487.

Grant S, London ED, Newlin DB, Villemagne VL, Liu X, Contoreggi C et al (1996). Activation of memory circuits during cue-elicited cocaine craving. Proc Natl Acad Sci USA 93: 12040-12045.

Gustafson L, Edvinsson L, Dahlgren N, Hagberg B, Risberg J, Rosen I et al (1987). Intravenous physostigmine treatment of Alzheimer's disease evaluated by psychometric testing, regional cerebral blood flow (rCBF) measurement, and EEG. Psychopharmacology (Berl) 93: 31-35.

Hasselmo ME (1995). Neuromodulation and cortical function: modeling the physiological basis of behavior. Behav Brain Res 67: 1-27.

Horner B, Scheibe K, Stine S (1996). Cocaine abuse and attentiondeficit hyperactivity disorder: implications of adult symptomatology. Psychol Addict Behav 10: 55-60.

Imperato A, Obinu MC, Gessa GL (1993a). Effects of cocaine and amphetamine on acetylcholine release in the hippocampus and caudate nucleus. Eur J Pharmacol 238: 377-381.

Imperato A, Obinu MC, Gessa GL (1993b). Stimulation of both dopamine D1 and D2 receptors facilitates in vivo acetylcholine release in the hippocampus. Brain Res 618: 341-345.

Imperato A, Obinu MC, Mascia MS, Casu MA, Zocchi A, Cabib S et al (1996). Strain-dependent effects of dopamine agonists on acetylcholine release in the hippocampus: an in vivo study in mice. Neuroscience 70: 653-660.

Jovanovski D, Erb S, Zakzanis KK (2005). Neurocognitive deficits in cocaine users: a quantitative review of the evidence. J Clin Exp Neuropsychol 27: 189-204.

Kalman D, Morissette SB, George TP (2005). Co-morbidity of smoking in patients with psychiatric and substance use disorders. Am J Addict 14: 106-123.

Karpen JW, Hess GP (1986). Cocaine, phencyclidine, and procaine inhibition of the acetylcholine receptor: characterization of the binding site by stopped-flow measurements of receptor-controlled ion flux in membrane vesicles. Biochemistry (Mosc) 25: $1777-1785$

Kilts CD, Schweitzer JB, Quinn CK, Gross RE, Faber TL, Muhammad $\mathrm{F}$ et al (2001). Neural activity related to drug craving in cocaine addiction. Arch Gen Psychiatry 58: 334-341. 
Koeppe RA, Frey KA, Snyder SE, Kilbourn MR, Kuhl DE (1997). Evaluation of two distinct kinetic analyses for use with [C-11]PMP: an irreversible tracer for mapping AChE activity. J Cereb Blood Flow Metab 17: S329.

Kosten TR, Scanley BE, Tucker KA, Oliveto A, Prince C, Sinha R et al (2006). Cue-induced brain activity changes and relapse in cocaine-dependent patients. Neuropsychopharmacology 31: 644-650.

Kotani S, Yamauchi T, Teramoto T, Ogura H (2008). Donepezil, an acetylcholinesterase inhibitor, enhances adult hippocampal neurogenesis. Chem Biol Interact 175: 227-230.

Kuhl DE, Koeppe RA, Minoshima S, Snyder SE, Ficaro EP, Foster NL et al (1999). In vivo mapping of cerebral acetylcholinesterase activity in aging and Alzheimer's disease. Neurology 52: 691-699.

Li CS, Kosten TR, Sinha R (2005). Sex differences in brain activation during stress imagery in abstinent cocaine users: a functional magnetic resonance imaging study. Biol Psychiatry 57: 487-494.

Lim KO, Choi SJ, Pomara N, Wolkin A, Rotrosen JP (2002). Reduced frontal white matter integrity in cocaine dependence: a controlled diffusion tensor imaging study. Biol Psychiatry 51: 890-895.

Lipton JW, Olsen RW, Ellison GD (1995). Length of continuous cocaine exposure determines the persistence of muscarinic and benzodiazepine receptor alterations. Brain Res 676: 378-385.

Maas LC, Lukas SE, Kaufman MJ, Weiss RD, Daniels SL, Rogers $\mathrm{VW}$ et al (1998). Functional magnetic resonance imaging of human brain activation during cue-induced cocaine craving. $\mathrm{Am}$ J Psychiatry 155: 124-126.

Macedo DS, Correia EE, Vasconcelos SM, Aguiar LM, Viana GS, Sousa FC (2004). Cocaine treatment causes early and longlasting changes in muscarinic and dopaminergic receptors. Cell Mol Neurobiol 24: 129-136.

Mansvelder HD, De Rover M, McGehee DS, Brussaard AB (2003). Cholinergic modulation of dopaminergic reward areas: upstream and downstream targets of nicotine addiction. Eur J Pharmacol 480: $117-123$.

Mark GP, Hajnal A, Kinney AE, Keys AS (1999). Self-administration of cocaine increases the release of acetylcholine to a greater extent than response-independent cocaine in the nucleus accumbens of rats. Psychopharmacology (Berl) 143: 47-53.

Matochik JA, London ED, Eldreth DA, Cadet JL, Bolla KI (2003). Frontal cortical tissue composition in abstinent cocaine abusers: a magnetic resonance imaging study. Neuroimage 19: 1095-1102.

Meador KJ, Loring DW, Hendrix N, Nichols ME, Oberzan R, Moore EE (1995a). Synergistic anticholinergic and antiserotonergic effects in humans. J Clin Exp Neuropsychol 17: 611-621.

Meador KJ, Loring DW, Hendrix N, Nichols ME, Oberzan R, Moore EE (1995b). Synergistic anticholingergic and antiserotonergic effects in humans. J Clin Exp Neuropsychol 17: 611-621.

Mesulam MM (1996). The systems-level organization of cholinergic innervation in the human cerebral cortex and its alterations in Alzheimer's disease. Prog Brain Res 109: 285-297.

Meyers RA, Zavala AR, Speer CM, Neisewander JL (2006). Dorsal hippocampus inhibition disrupts acquisition and expression, but not consolidation, of cocaine conditioned place preference. Behav Neurosci 120: 401-412.

Namba H, Iyo M, Fukushi K, Shinotoh H, Nagatsuka S, Suhara T et al (1999). Human cerebral acetylcholinesterase activity measured with positron emission tomography: procedure, normal values and effect of age. Eur J Nucl Med 26: 135-143.

Naqvi NH, Rudrauf D, Damasio H, Bechara A (2007). Damage to the insula disrupts addiction to cigarette smoking. Science 315: 531-534.

Noonan MA, Choi KH, Self DW, Eisch AJ (2008). Withdrawal from cocaine self-administration normalizes deficits in proliferation and enhances maturity of adult-generated hippocampal neurons. J Neurosci 28: 2516-2526.
Paulus MP, Tapert SF, Schuckit MA (2005). Neural activation patterns of methamphetamine-dependent subjects during decision making predict relapse. Arch Gen Psychiatry 62: 761-768.

Ragozzino ME, Choi D (2004). Dynamic changes in acetylcholine output in the medial striatum during place reversal learning. Learn Mem 11: 70-77.

Reiman EM, Lane RD, Ahern GL, Schwartz GE, Davidson RJ, Friston KJ et al (1997). Neuroanatomical correlates of externally and internally generated human emotion. Am J Psychiatry 154: 918-928.

Risinger RC, Salmeron BJ, Ross TJ, Amen SL, Sanfilipo M, Hoffmann RG et al (2005). Neural correlates of high and craving during cocaine self-administration using BOLD fMRI. Neuroimage 26: 1097-1108.

Robbins TW (2002). The 5-choice serial reaction time task: behavioural pharmacology and functional neurochemistry. Psychopharmacology (Berl) 163: 362-380.

Robinson SE, Hambrecht KL (1988). The effect of cocaine on hippocampal cholinergic and noradrenergic metabolism. Brain Res 457: 383-385.

Rose JE, Behm FM, Westman EC, Mathew RJ, London ED, Hawk TC et al (2003). PET studies of the influences of nicotine on neural systems in cigarette smokers. Am J Psychiatry 160: 323-333.

Sarter M, Bruno JP, Givens B (2003). Attentional functions of cortical cholinergic inputs: what does it mean for learning and memory? Neurobiol Learn Mem 80: 245-256.

Sasaki M, Tohyama K, Matsunaga S, Nakamura M, Tomizawa N, Inoue T et al (2004). MRI identification of dorsal hippocampus homologue in human brain. Neuroreport 15: 2173-2176.

Schroeder JP, Packard MG (2004). Facilitation of memory for extinction of drug-induced conditioned reward: role of amygdala and acetylcholine. Learn Mem 11: 641-647.

See RE, McLaughlin J, Fuchs RA (2003). Muscarinic receptor antagonism in the basolateral amygdala blocks acquisition of cocaine-stimulus association in a model of relapse to cocaineseeking behavior in rats. Neuroscience 117: 477-483.

Seeger T, Fedorova I, Zheng F, Miyakawa T, Koustova E, Gomeza J et al (2004). M2 muscarinic acetylcholine receptor knock-out mice show deficits in behavioral flexibility, working memory, and hippocampal plasticity. J Neurosci 24: 10117-10127.

Sharkey J, Ritz MC, Schenden JA, Hanson RC, Kuhar MJ (1988a). Cocaine inhibits muscarinic cholinergic receptors in heart and brain. J Pharmacol Exp Ther 246: 1048-1052.

Sharkey J, Ritz MC, Schenden JA, Hanson RC, Kuhar MJ (1988b). Cocaine inhibits muscarinic cholinergic receptors in heart and brain. J Pharmacol Exp Ther 246: 1048-1052.

Smith JE, Co C, Yin X, Sizemore GM, Liguori A, Johnson III WE et al (2004a). Involvement of cholinergic neuronal systems in intravenous cocaine self-administration. Neurosci Biobehav Rev 27: 841-850.

Smith JE, Vaughn TC, Co C (2004b). Acetylcholine turnover rates in rat brain regions during cocaine self-administration. J Neurochem 88: 502-512.

Smith YR, Minoshima S, Kuhl DE, Zubieta JK (2001). Effects of long-term hormone therapy on cholinergic synaptic concentrations in healthy postmenopausal women. J Clin Endocrinol Metab 86: 679-684.

Sobell MB, Sobell LC (1978). Behavioral Treatment of Alcohol Problems. Plenum Press: NewYork.

Sousa FC, Gomes PB, Macedo DS, Marinho MM, Viana GS (1999). Early withdrawal from repeated cocaine administration upregulates muscarinic and dopaminergic D2-like receptors in rat neostriatum. Pharmacol Biochem Behav 62: 15-20.

Thomsen M, Woldbye DP, Wortwein G, Fink-Jensen A, Wess J, Caine SB (2005). Reduced cocaine self-administration in muscarinic M5 acetylcholine receptor-deficient mice. J Neurosci 25: 8141-8149. 
Weddington WW, Brown BS, Haertzen CA, Cone EJ, Dax EM, Herning RI et al (1990). Changes in mood, craving, and sleep during short-term abstinence reported by male cocaine addicts. Arch Gen Psychiatry 47: 861-868.

Weiner DM, Levey AI, Brann MR (1990). Expression of muscarinic acetylcholine and dopamine receptor mRNAs in rat basal ganglia. Proc Natl Acad Sci USA 87: 7050-7054.

Williams MJ, Adinoff B (2008). The role of acetylcholine in cocaine addiction. Neuropsychopharmacology 33: 1779-1797.

Wilson MC, Schuster CR (1973). Cholinergic influence on intravenous cocaine self-administration by rhesus monkeys. Pharmacol Biochem Behav 1: 643-649.

Winhusen TM, Somoza EC, Harrer JM, Mezinskis JP, Montgomery MA, Goldsmith RJ et al (2005). A placebo-controlled screening trial of tiagabine, sertraline and donepezil as cocaine dependence treatments. Addiction 100(Suppl 1): 68-77.

Yamaguchi M, Suzuki T, Seki T, Namba T, Juan R, Arai $H$ et al (2004). Repetitive cocaine administration decreases neurogenesis in adult rat hippocampus. Ann NY Acad Sci 1025: 351-362.

Yeomans J, Forster G, Blaha C (2001). M5 muscarinic receptors are needed for slow activation of dopamine neurons and for rewarding brain stimulation. Life Sci 68: 2449-2456.

Zeigler S, Lipton J, Toga A, Ellison G (1991). Continuous cocaine administration produces persisting changes in brain neurochemistry and behavior. Brain Res 552: 27-35.

Zhang W, Yamada M, Gomeza J, Basile AS, Wess J (2002). Multiple muscarinic acetylcholine receptor subtypes modulate striatal dopamine release, as studied with M1-M5 muscarinic receptor knock-out mice. J Neurosci 22: 6347-6352.

Zhou FM, Wilson C, Dani JA (2003). Muscarinic and nicotinic cholinergic mechanisms in the mesostriatal dopamine systems. Neuroscientist 9: 23-36.

Zubieta JK, Heitzeg MM, Xu Y, Koeppe RA, Ni L, Guthrie S et al (2005). Regional cerebral blood flow responses to smoking in tobacco smokers after overnight abstinence. Am J Psychiatry 162: 567-577.

Supplementary Information accompanies the paper on the Neuropsychopharmacology website (http://www.nature.com/npp) 